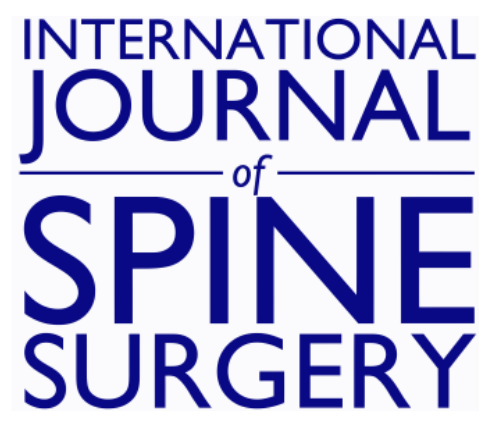

\title{
Risk Factors for Acute Surgical Site Infection after Spinal Instrumentation Procedures: A Case-Control Study
}

Tiago Amorim-Barbosa, Ricardo Sousa, Ricardo Rodrigues-Pinto and António Oliveira

Int J Spine Surg 2021, 15 (5) 1025-1030

doi: https://doi.org/10.14444/8130

http://ijssurgery.com/content/15/5/1025

This information is current as of April 26, 2023.

Email Alerts Receive free email-alerts when new articles cite this article. Sign up at:

http://ijssurgery.com/alerts

The International Journal of Spine Surgery

2397 Waterbury Circle, Suite 1,

Aurora, IL 60504, Phone: +1-630-375-1432 


\title{
Risk Factors for Acute Surgical Site Infection after Spinal Instrumentation Procedures: A Case-Control Study
}

\author{
TIAGO AMORIM-BARBOSA, MD, ${ }^{1}$ RICARDO SOUSA, MD, PHD, ${ }^{1,2}$ \\ RICARDO RODRIGUES-PINTO, MD, PHD, FEBOT, ${ }^{1,3,4}$ ANTÓNIO OLIVEIRA, MD, PHD ${ }^{1,3}$ \\ ${ }^{1}$ Department of Orthopaedics, Centro Hospitalar Universitário do Porto-Hospital de Santo António, Porto, Portugal, ${ }^{2}$ Porto Bone and Joint Infection Group, Porto, \\ Portugal, ${ }^{3}$ Instituto de Ciências Biomédicas Abel Salazar, Porto, Portugal, ${ }^{4}$ Spinal Unit (UVM), Department of Orthopaedics, Centro Hospitalar do Porto, Portugal
}

\begin{abstract}
Background: Surgical site infection (SSI) prevalence in spinal instrumentation varies, depending on patient and surgery factors. This study aims to identify patient- and procedure-related factors associated with SSI after spinal instrumentation in 3 patient-specific groups: those undergoing surgery for degenerative, trauma-related, and pediatric deformity conditions.

Methods: A case-control (1:2 ratio) analysis of SSI after spinal instrumentation, from 2009 to 2017, in a University Hospital and Spinal Trauma Centre was performed.

Results: From a total of 2582 surgeries, 33 cases $(1.3 \%)$ were identified with SSI according to study inclusion criteria: 14 (out of 1326) in the degenerative group, 11 (out of 207) in the trauma group, and 8 (out of 850) in the pediatric deformity group. Cases were matched with controls $(\mathrm{n}=66)$ of the same group. Univariate analysis identified procedure and anesthesia duration in the degenerative group $(P=.032$ and .038 , respectively), age $(P=.014)$ and need for intraoperative and postoperative blood transfusions (both $P=.039$ ) in the trauma group and American Society of Anesthesiologists score $(P=.022)$ and neuromuscular scoliosis $(P=.002)$ in the pediatric deformity group as associated with SSI. After multivariate analysis, procedure duration was independently associated with SSI in degenerative surgery (odds ratio [OR], 2.23; 95\% confidence interval [CI], 1.03-4.82) and procedure duration (OR, 3.79; 95\% CI, 1.27-11.32) and number of levels instrumented (OR, 11.77; 95\% CI, 1.55-89.40) in the trauma group.

Conclusions: This study identified procedure duration as a risk factor for SSI after spinal instrumentation in degenerative and trauma spine surgery and the number of levels instrumented in trauma spine surgery. Awareness of these factors will help develop strategies to improve patient and health system overall outcomes.

Complications

Keywords: risk factors, spinal fusion, spinal instrumentation, surgical site infection
\end{abstract}

\section{INTRODUCTION}

Surgical site infection (SSI) is one of the most common and serious complications following spinal surgery. It results in increased rates of morbidity, mortality, and health care costs, often requiring surgical debridement, long-term antibiotics, and hardware removal. ${ }^{1}$ Even after successful treatment of the infected area, a postoperative infection has a negative emotional impact on a patient's overall outcome. $^{2}$

The prevalence of SSI reported in the literature ranges from $0.7 \%$ to $12.0 \%$, depending on the indication for surgery and the type of surgery performed. ${ }^{3-5}$ Naturally, more complex procedures result in higher infection rates since the nature of the procedure accounts for the variability of the infection risk; for instance, the rate of infection after simple discectomy or laminectomy is approximately $1 \%$, whereas spinal fusion has rates of $2 \%-$ $5 \%$. 4,6

Given the ongoing substantial clinical and economic impact of SSIs, efforts to reduce their occurrence are critically needed. One of the most important first steps in reducing the incidence of SSIs is to identify risk factors for their occurrence. Improved understanding of potentially modifiable risk factors, and even those that are not modifiable, may lead to systematic changes that can influence the selection of patients for surgery or type of surgical procedure performed, decreasing SSI risk on a large scale and improving patients' overall outcome.

Among published studies of SSIs complicating spine surgery, there has been much variation in patient population. ${ }^{7,8}$ A relatively limited number of 
studies were conducted specifically following spinal fusion surgery and even fewer on specific groups of patients such as those undergoing degenerative, trauma or pediatric spinal deformity surgery.

The goal of this study was to assess risk factors for SSI after different specific spinal fusion procedures performed for degenerative conditions, traumatic injury, or pediatric spinal deformity, in order to develop effective prevention strategies.

\section{METHODS}

A retrospective study was conducted with patients who underwent lumbar spinal instrumentation between January 2009 and August 2017 in a university hospital and tertiary spinal trauma center. The study protocol was approved by the institutional review board of the hospital. Patients were categorized in 3 groups: (1) fusion for lumbar spinal degenerative diseases, which includes fusion for spinal stenosis, disc herniation, spondylolisthesis or adult degenerative deformity; (2) spinal instrumentation/fusion for fractures; and (3) fusion for pediatric spinal deformity. Cases were identified by monitoring positive wound culture reports and readmissions with a minimum 1-year follow-up, according to the Centers for Disease Control and Prevention criteria. ${ }^{9,10}$ Patients who underwent fusion through an anterior approach were excluded from this study because anterior approach procedures have a significantly lower infection rate than procedures involving a posterior approach. ${ }^{8,11}$ Patients undergoing fusion surgery for tumors and cases with negative wound cultures were also excluded from analysis.

Each case patient was matched with a control (1:2 ratio) of the same preoperative diagnosis (degeneration, trauma, or pediatric deformity), with surgery performed immediately before and immediately after the index case, using a previously described methodology. ${ }^{12}$

Electronic and paper medical records were retrospectively reviewed for all cases and controls. Patient-related variables included demographic data (age and sex), body mass index, the American Society of Anesthesiologists (ASA) physical status classification system, presence of diabetes mellitus, current tobacco use, preoperative hemoglobin value, and previous spine intervention. The indication for each surgical procedure was categorized as degenerative spine disease, trauma, or pediatric spinal deformity.
Intraoperative parameters collected included number of instrumented levels, type of bone graft used (local autograft alone, iliac crest bone graft, allograft) and cage use, vertebral region involved, estimated intraoperative blood loss, procedure and anesthesia duration, blood transfusion requirements, appropriate antibiotic prophylaxis (intravenous cefazolin or clindamycin administered within 60 minutes of incision, and repeated for procedures exceeding 240 minutes). Postoperative risk factors assessed included blood transfusion requirements, total hospital length of stay, and placement and duration of drains.

\section{Statistical Methods}

Statistical analysis was performed using SPSS 25.0. Univariate analysis was conducted to identify the potential risk factors for SSI using Student $t$ tests for continuous data and $\chi^{2}$ tests for dichotomous data. Multivariate logistic regression analysis was performed to determine the independent risk factors by systematically pruning the least significant variables out of a multiple logistic regression model that initially included all variables. A significant difference was set as $P<.05$.

\section{RESULTS}

During the study period, from a total of 2582 surgeries, 33 cases $(1.3 \%)$ were identified with SSI according to study inclusion criteria: 14 (out of 1326) in the degenerative group, 11 (out of 207) in the trauma group, and 8 (out of 850) in the pediatric spinal deformity group. Each case was paired with 2 controls with a total of 66 patients. Infections were diagnosed a mean of 76 days postprocedure (range: 15-330 days). Twenty-seven patients (82\%) underwent at least 1 reoperation to treat the infection with debridement of the infected tissue.

The most common microorganism isolated from the cultures obtained from the surgical wounds was Staphylococcus aureus, which was found in 22 cases, 12 of which were methicillin resistant. Most of the cases were monomicrobial, but in 10 cases $(30 \%)$ a polymicrobial infection was found. Table 1 provides a summary of the microorganisms identified in the reported infections.

Univariate analysis of patient- and surgeryrelated risk factors associated with spinal fusion surgical site infection is presented on Table 2. In the degenerative group, statistically significant differ- 
Table 1. Clinical features of cases of surgical site infection following spinal fusion procedures.

\begin{tabular}{lc}
\hline Pathogens & Value, $\mathbf{n}=\mathbf{3 3}$ \\
\hline Gram-positive, n (\%) & \\
Staphylococcus aureus, methicillin susceptible & $12(36)$ \\
Staphylococcus aureus, methicillin resistant & $10(30)$ \\
Coagulase-negative staphylococci & $5(15)$ \\
Others & \\
$\quad$ Enterococcus faecalis & $2(6)$ \\
$\quad$ Streptococcus mitis & $1(3)$ \\
Streptococcus salivarius & $1(3)$ \\
Gram-negative, n (\%) & \\
Enterobacteriaceae & $3(9)$ \\
Escherichia coli & $1(9)$ \\
Proteus mirabilis & $4(12)$ \\
Klebsiella pneumoniae & $1(9)$ \\
Enterobacter aerogenes & $1(9)$ \\
Morganella morganii & $2(6)$ \\
Pseudomonas aeruginosa & \\
Others, n (\%) & $2(6)$ \\
Acinetobacter baumanni & $10(30)$ \\
Polymicrobial & 76 \\
Time to SSI diagnosis, d & $27(82)$ \\
Surgical treatment, yes, n (\%) &
\end{tabular}

Abbreviation: SSI, surgical site infection.

ences were found in surgery duration $(175 \pm 53$ $[$ mean $\pm \mathrm{SD}]$ minutes in cases and $136 \pm 54$ minutes in controls, $P=.032$ ) and anesthesia duration $(233 \pm 65$ minutes in cases and $190 \pm 60$ minutes in controls, $P=.038)$. In the trauma group, among patient-related risk factors, cases were significantly older $(67 \pm 16$ versus $48 \pm 20$ years old, $P=.014)$ when compared with controls. Cases
Table 3. Multivariate logistic regression model for surgical site infection after spine instrumentation.

\begin{tabular}{lcrc}
\hline Multivariate Analysis & $\boldsymbol{P}$ & OR & $\mathbf{9 5 \%}$ CI \\
\hline $\begin{array}{l}\text { Denegerative } \\
\quad \text { Procedure duration, h }\end{array}$ & .041 & 2.23 & $1.03-4.82$ \\
$\quad$ Trauma & & & \\
$\quad$ Procedure duration, h & .017 & 3.79 & $1.27-11.32$ \\
$\quad$ Length of instrumentation (lvl) & .017 & 11.77 & $1.55-89.40$ \\
\hline
\end{tabular}

Abbreviations: CI, confidence interval; lvl, number of levels; OR, odds ratio.

had higher blood transfusion requirements during and after surgery compared with controls (both $P=$ .039). In the pediatric deformity group, cases presented a higher ASA score when compared with controls $(P=.022)$ and SSI occurred more frequently in neuromuscular scoliosis in comparison with idiopathic scoliosis $(P=.002)$.

After multivariate analysis (Table 3 ), procedure duration was the only statistically significant independent risk factor for SSI in degenerative surgery, so that each additional hour of surgery doubled the risk for SSI (odds ratio [OR], 2.23; 95\% confidence interval $[\mathrm{CI}], 1.03-4.82)$. In the trauma group, this difference was even more pronounced, with an almost fourfold higher SSI risk for each additional hour of surgery (OR, 3.79; 95\% CI, 1.27-11.32). Also, in trauma spine surgery, a supplemental level of instrumentation represented a 12 -fold increased

Table 2. Univariate analysis of patient-related and surgery-related risk factors associated with spinal fusion surgical site infection.

\begin{tabular}{|c|c|c|c|c|c|c|c|c|c|}
\hline \multirow[b]{2}{*}{ Univariate Analysis } & \multicolumn{3}{|c|}{ Degenerative } & \multicolumn{3}{|c|}{ Trauma } & \multicolumn{3}{|c|}{ Pediatric Spinal Deformity } \\
\hline & $\begin{array}{c}\text { Cases } \\
(\mathrm{n}=14) \\
\mathrm{n}(\%)\end{array}$ & $\begin{array}{c}\text { Controls } \\
(\mathrm{n}=28), \\
\mathbf{n}(\%)\end{array}$ & $P$ & $\begin{array}{c}\text { Cases } \\
(\mathbf{n}=11) \\
\mathbf{n}(\%)\end{array}$ & $\begin{array}{c}\text { Controls } \\
(\mathbf{n}=22) \\
\text { n }(\%)\end{array}$ & $\boldsymbol{P}$ & $\begin{array}{c}\text { Cases } \\
(n=8) \\
n(\%)\end{array}$ & $\begin{array}{c}\text { Controls } \\
(\mathbf{n}=16), \\
n(\%)\end{array}$ & $\boldsymbol{P}$ \\
\hline Sex (male) & $5(36)$ & $7(25)$ & ns & $8(73)$ & $12(55)$ & ns & $3(38)$ & $4(25)$ & ns \\
\hline Age (years) & $60(13)$ & $62(17)$ & ns & $67(16)$ & $48(20)$ & .014 & $16(3)$ & $16(2)$ & ns \\
\hline BMI $\left(\mathrm{kg} / \mathrm{m}^{2}\right)$ & $28(3)$ & $28(5)$ & ns & $25(2)$ & $26(4)$ & ns & $20(3)$ & $23(6)$ & ns \\
\hline Diabetes mellitus & $0(0)$ & $3(11)$ & ns & $1(9)$ & $1(4,5)$ & ns & $0(0)$ & $0(0)$ & ns \\
\hline Tobacco use & $1(7,2)$ & $1(3,6)$ & ns & $3(27)$ & $4(18)$ & ns & $0(0)$ & $1(6)$ & ns \\
\hline $\mathrm{ASA} \geq 3$ & $3(21)$ & $5(20)$ & ns & $5(46)$ & $5(23)$ & ns & $4(50)$ & $0(0)$ & .002 \\
\hline Previous surgery & $4(29)$ & $2(7)$ & ns & $1(9)$ & $1(4,5)$ & ns & $0(0)$ & $0(0)$ & ns \\
\hline Preoperative hemoglobin $(\mathrm{g} / \mathrm{dL})$ & $13.6(2.2)$ & $13.3(1,7)$ & ns & $13.6(1.6)$ & $13.7(1.6)$ & ns & $13.7(1.1)$ & $13.9(0.9)$ & ns \\
\hline Length of instrumentation (lvl) & 1,5 & 2,2 & ns & 3 & 2 & ns & 13 & 11 & ns \\
\hline \multicolumn{10}{|l|}{ Materials } \\
\hline Autograft alone & $9(64)$ & $17(61)$ & ns & $1(9)$ & $1(4,5)$ & ns & $6(75)$ & $15(94)$ & ns \\
\hline Iliac crest bone graft & $1(7,2)$ & $1(3,6)$ & ns & $0(0)$ & $0(0)$ & ns & $0(0)$ & $0(0)$ & ns \\
\hline Cage & $0(0)$ & $5(18)$ & ns & $0(0)$ & $0(0)$ & ns & $0(0)$ & $0(0)$ & ns \\
\hline Others & $0(0)$ & $0(0)$ & ns & $0(0)$ & $0(0)$ & ns & $2(25)$ & $0(0)$ & ns \\
\hline EBL (mL) & 380 & 323 & ns & 145 & 111 & ns & 1010 & 1048 & ns \\
\hline Intraoperative transfusion (yes) & $2(15)$ & $2(8)$ & ns & $2(18)$ & $0(0)$ & .039 & $2(25)$ & $2(13)$ & ns \\
\hline Postoperative transfusion (yes) & $3(21)$ & $3(11)$ & ns & $2(18)$ & $0(0)$ & .039 & $4(50)$ & $8(50)$ & ns \\
\hline Antibiotics & $11(79)$ & $24(86)$ & ns & $10(91)$ & $18(82)$ & ns & $8(100)$ & $15(94)$ & ns \\
\hline Procedure duration (min) & $175(53)$ & $136(54)$ & .032 & $193(45)$ & $107(38)$ & ns & $183(27)$ & $183(44)$ & ns \\
\hline Anesthesia duration (min) & $234(65)$ & $191(60)$ & .038 & $264(48)$ & $168(51)$ & ns & $282(44)$ & $244(48)$ & ns \\
\hline Drainage placement (yes) & $2(15)$ & $12(43)$ & ns & $1(9)$ & $0(0)$ & ns & $1(13)$ & $3(19)$ & ns \\
\hline Drainage duration, $\mathrm{d}$ & 1 & 1 & ns & 1 & - & ns & 1 & 1 & ns \\
\hline Length of hospital stay, d & 20 & 6 & ns & 52 & 6 & ns & 10 & 5 & ns \\
\hline Neuromuscular scoliosis & na & na & & na & na & & $4(50)$ & $0(0)$ & .002 \\
\hline
\end{tabular}

Abbreviations: ASA, American Society of Anesthesiologists; BMI, body mass index; EBL, estimated blood loss; lvl, number of levels; ns, not significant. 
risk for SSI (OR, 11.77; 95\% CI, 1.55-89.40). In the pediatric deformity group, no statistically significant results were found in multivariate analysis.

\section{DISCUSSION}

SSI is one of the most frequent and feared complications after spinal instrumentation surgery, representing an increase in morbidity and mortality for patients, considering the necessity for reoperation and long-term antibiotic therapy, as well as the potential need for hardware removal and potential risk of nonunion. Furthermore, SSI is a major driver of increased health-care costs, since it leads to prolonged care and therapy, unplanned hospital readmission, and delayed return to work. Because of its relevance, numerous studies have been carried out to identify risk factors associated with SSI after spinal surgery and several have been detected. . $^{72,13}$ However, most of these studies included mixed populations with and without spinal instrumentation, and are mainly focused on patients with degenerative disorders. It has been previously shown that the risk of SSI is greater in patients undergoing instrumentation compared to patients in whom only decompression is performed. ${ }^{14,15}$

In addition, previous studies include cases of infection of patients with different spine pathologies, making an overall analysis of these patients difficult and biased. This is because degenerative pathology, spinal trauma, and pediatric spine deformity have their own characteristics related to patients and procedures, which require an independent analysis of these risk factors.

Taking these aspects into consideration, the objective of the present study was to identify risk factors for patient-dependent SSI in groups of patients with degenerative disease, traumatic injury, and pediatric spinal deformities undergoing spinal instrumentation surgery.

In this study, the duration of the procedure in the degenerative and trauma surgery groups presented as an independent risk factor for SSI with an increased risk of 2- and 4-fold, respectively, as previous demonstrated. ${ }^{8}$ A greater extension of instrumentation is also a previously identified risk factor for SSI. ${ }^{3,16,17}$ Since increasing the number of spinal levels fused will tend to require increased operative time, these procedure-related factors are likely linked, which may complicate the ability to assess them independently. Despite the statistically significant differences in univariate analysis in age (trauma surgery) and ASA score (pediatric spine deformities), these results were not confirmed in the multivariate analysis model. On the other hand, potentially modifiable factors such as obesity, ${ }^{18,19}$ diabetes mellitus, ${ }^{16,20}$ and smoking status ${ }^{21}$ all of which are frequently associated with SSI and confirmed in multiple studies of spine surgery, were also not observed, so definitive conclusions could not be drawn based on the current data. Nevertheless, they should be considered.

The same applies to the etiology of scoliosis, which is a known strong determinant of infection rate. As reported by previous studies, the rate of wound infection after surgery for neuromuscular scoliosis ranges from $4 \%$ to $14 \% .^{22}$ However, the corresponding infection rate ranges from $1 \%$ to $3 \%$ in idiopathic scoliosis. ${ }^{23}$ Patients with neuromuscular scoliosis stay in the intensive care unit during the postoperative period, are often nonambulatory, and may have difficulty in performing personal hygiene and poor preoperative nutrition, which may directly contribute to the higher risk of postoperative infection. $^{24}$

Although the risk factors that we were able to highlight are generally well recognized, strategies to address these risk factors are not consistently applied. In the setting of elective spinal fusion, preoperative management of modifiable risk factors may help to reduce the risk of SSI. According to our study, when feasible, modification of surgical strategies may offer additional opportunities to reduce the risk of SSI, including: minimizing the number of spinal levels to be fused and employing strategies to minimize operative time (eg, use of 2 attending surgeons for more complex cases). ${ }^{8}$ Even after controlling for all the previously described factors, adjuvant strategies can be implemented in high-risk populations with neuromuscular scoliosis or advanced age, or during long spine instrumentations, which proved to greatly decrease the incidence of postsurgical wound SSI following spinal surgeries.

The application of local vancomycin in powder form within the surgical wound as an adjunct to parenteral antibiotics to decrease the risk of SSI has gained widespread popularity among spine surgeons. Intrawound vancomycin powder appears to be a promising option for additional antibiotic prophylaxis due to its low cost, extensive availability, ease of application, good safety profile, and perception of effectiveness against most commonly 
isolated pathogens in SSI such as gram-positive including methicillin-resistant Staphylococcus aureus and multidrug-resistant Staphylococcus epidermidis. ${ }^{25,26}$ Although development of vancomycinresistant pathogens is a reasonable concern, evidence to date does not show an increase in SSI caused by such pathogens in patients who received intrawound vancomycin. ${ }^{27}$

Regarding antibiotic perioperative prophylaxis, in addition to the usual cefazolin within 1 hour before skin incision, ${ }^{28}$ intraoperative redosing also appears to reduce SSI risk in operations lasting longer than 4 hours. ${ }^{29}$ There is a strong recommendation to limit the use of perioperative antibiotic prophylaxis to 24 hours and avoiding the use of broader-spectrum antimicrobials, even in the presence of long instrumentations or using of closed suction drains for more than 24 hours. ${ }^{26}$

Closed suction drains have been used to decrease the rate of postoperative hematoma formation and thus SSIs. However contrary to previous beliefs, there is no difference in the incidence of hematoma, superficial wound infection, or deep infection in patients with versus patients without closed suction drains after lumbar surgery. ${ }^{30,31}$ Therefore, spine surgeons should not routinely rely on closed suction drains and the decision regarding its use should be individualized.

Closed-incision negative-pressure wound therapy and silver-impregnated dressings have been adapted by many spine surgeons as a safe and effective means of wound management in patients with increased risk of SSIs after spinal procedures; however, current evidence does not include sufficient high-level evidence defining the specific indications for its use in spine patients. ${ }^{26}$

Whenever possible, a minimally invasive approach should be considered, as it presents a lower risk of SSI than open approaches. ${ }^{32}$

The major limitation of this study was its retrospective design, so the accuracy of the data was dependent on the documentation inserted into electronic and paper medical records. Additionally, this is a single-institution study, with a limited dataset, and the lack of significance of some of the parameters of potential interest may reflect insufficient statistical power.

\section{CONCLUSION}

This study identified procedure duration as a risk factor for SSI after spinal instrumentation in degenerative and trauma spine surgery; the number of levels instrumented was an additional risk factor in trauma spine surgery. Awareness of these factors will help to develop strategies to improve patient and health system overall outcomes.

\section{REFERENCES}

1. Kirkland KB, Briggs JP, Trivette SL, Wilkinson WE, Sexton DJ. The impact of surgical-site infections in the 1990s: attributable mortality, excess length of hospitalization, and extra costs. Infect Control Hosp Epidemiol. 1999;20(11):725730. doi:10.1086/501572

2. Sasso RC, Garrido BJ. Postoperative spinal wound infections. J Am Acad Orthop Surg. 2008;16(6):330-337.

3. Fang A, Hu SS, Endres N, Bradford DS. Risk factors for infection after spinal surgery. Spine (Phila Pa 1976). 2005;30(12):1460-1465.

4. Weinstein MA, McCabe JP, Cammisa FP Jr. Postoperative spinal wound infection: a review of 2,391 consecutive index procedures. J Spinal Disord. 2000;13(5):422-426.

5. Olsen MA, Nepple JJ, Riew KD, et al. Risk factors for surgical site infection following orthopaedic spinal operations. $J$ Bone Joint Surg Am. 2008;90(1):62-69. doi:10.2106/JBJS.F. 01515

6. Edwards JR, Peterson KD, Mu Y, et al. National Healthcare Safety Network (NHSN) report: data summary for 2006 through 2008, issued December 2009. Am J Infect Control.Dec2009;37(10):783-805. doi:10.1016/j.ajic.2009.10.001

7. Schimmel JJ, Horsting PP, de Kleuver M, Wonders G, van Limbeek J. Risk factors for deep surgical site infections after spinal fusion. Eur Spine J. 2010;19(10):1711-1719. doi:10. 1007/s00586-010-1421-y

8. Pesenti S, Pannu T, Andres-Bergos J, et al. What are the risk factors for surgical site infection after spinal fusion? A meta-analysis. Eur Spine J. 2018;27(10):2469-2480. doi:10.1007/ s00586-018-5733-7

9. Horan TC, Gaynes RP, Martone WJ, Jarvis WR, Emori TG. CDC definitions of nosocomial surgical site infections, 1992: a modification of CDC definitions of surgical wound infections. Infect Control Hosp Epidemiol. 1992;13(10):606-608.

10. Horan TC, Andrus M, Dudeck MA. CDC/NHSN surveillance definition of health care-associated infection and criteria for specific types of infections in the acute care setting. Am J Infect Control. 2008;36(5):309-332. doi:10.1016/j.ajic. 2008.03.002

11. Pull ter Gunne AF, Cohen DB. Incidence, prevalence, and analysis of risk factors for surgical site infection following adult spinal surgery. Spine (Phila Pa 1976). 2009;34(13):14221428. doi:10.1097/BRS.0b013e3181a03013

12. Lai Q, Song Q, Guo R, et al. Risk factors for acute surgical site infections after lumbar surgery: a retrospective study. J Orthop Surg Res. 2017;12(1):116. doi:10.1186/s13018017-0612-1

13. Liu JM, Deng HL, Chen XY, et al. Risk factors for surgical site infection after posterior lumbar spinal surgery. Spine (Phila Pa 1976). 2018;43(10):732-737. doi:10.1097/BRS. 0000000000002419

14. Ho C, Sucato DJ, Richards BS. Risk factors for the development of delayed infections following posterior spinal fusion and instrumentation in adolescent idiopathic scoliosis 
patients. Spine (Phila Pa 1976). 2007;32(20):2272-2277. doi:10. 1097/BRS.0b013e31814b1c0b

15. Linam WM, Margolis PA, Staat MA, et al. Risk factors associated with surgical site infection after pediatric posterior spinal fusion procedure. Infect Control Hosp Epidemiol. 2009;30(2):109-116. doi:10.1086/593952

16. Abdul-Jabbar A, Takemoto S, Weber MH, et al. Surgical site infection in spinal surgery: description of surgical and patientbased risk factors for postoperative infection using administrative claims data. Spine (Phila Pa 1976). 2012;37(15):1340-1345. doi:10.1097/BRS.0b013e318246a53a

17. Kurtz SM, Lau E, Ong KL, et al. Infection risk for primary and revision instrumented lumbar spine fusion in the Medicare population. J Neurosurg Spine. 2012;17(4):342-347. doi:10.3171/2012.7.SPINE12203

18. Lieber B, Han B, Strom RG, et al. Preoperative predictors of spinal infection within the National Surgical Quality Inpatient Database. World Neurosurg. 2016;89:517524. doi:10.1016/j.wneu.2015.12.085

19. Kalanithi PA, Arrigo R, Boakye M. Morbid obesity increases cost and complication rates in spinal arthrodesis. Spine (Phila Pa 1976). 2012;37(11):982-988. doi:10.1097/BRS. 0b013e31823bbeef

20. Browne JA, Cook C, Pietrobon R, Bethel MA, Richardson WJ. Diabetes and early postoperative outcomes following lumbar fusion. Spine (Phila Pa 1976). 2007;32(20):2214-2219. doi:10. 1097/BRS.0b013e31814b1bc0

21. Veeravagu A, Patil CG, Lad SP, Boakye M. Risk factors for postoperative spinal wound infections after spinal decompression and fusion surgeries. Spine (Phila Pa 1976). 2009;34(17):1869-1872. doi:10.1097/BRS.0b013e3181adc989

22. Cahill PJ, Warnick DE, Lee MJ, et al. Infection after spinal fusion for pediatric spinal deformity: thirty years of experience at a single institution. Spine (Phila Pa 1976). 2010;35(12):1211-1217. doi:10.1097/BRS.0b013e3181c212d1

23. Rihn JA, Lee JY, Ward WT. Infection after the surgical treatment of adolescent idiopathic scoliosis: evaluation of the diagnosis, treatment, and impact on clinical outcomes. Spine (Phila Pa 1976). 2008;33(3):289-294. doi:10.1097/BRS. 0b013e318162016e

24. Jevsevar DS, Karlin LI. The relationship between preoperative nutritional status and complications after an operation for scoliosis in patients who have cerebral palsy. $J$ Bone Joint Surg Am. 1993;75(6):880-884.

25. Xie LL, Zhu J, Yang MS, et al. Effect of intra-wound vancomycin for spinal surgery: a systematic review and metaanalysis. Orthop Surg. 2017;9(4):350-358. doi:10.1111/os.12356

26. Atesok K, Papavassiliou E, Heffernan MJ, et al. Current strategies in prevention of postoperative infections in spine surgery. Global Spine J. 2020;10(2):183-194. doi:10.1177/ 2192568218819817

27. Chotai S, Wright PW, Hale AT, et al. Does intrawound vancomycin application during spine surgery create vancomycin-resistant organism? Neurosurgery. 2017;80(5):746-753. doi:10.1093/neuros/nyw097

28. Watters WC, Baisden J, Bono CM, et al. Antibiotic prophylaxis in spine surgery: an evidence-based clinical guideline for the use of prophylactic antibiotics in spine surgery. Spine J. 2009;9(2):142-146. doi:10.1016/j.spinee.2008. 05.008

29. Steinberg JP, Braun BI, Hellinger WC, et al. Timing of antimicrobial prophylaxis and the risk of surgical site infections: results from the Trial to Reduce Antimicrobial Prophylaxis Errors. Ann Surg. 2009;250(1):10-16. doi:10.1097/SLA. 0b013e3181ad5fca

30. Liu JM, Chen WZ, Fu BQ, Chen JW, Liu ZL, Huang $\mathrm{SH}$. The use of closed suction drainage in lumbar spinal surgery: is it really necessary? World Neurosurg. 2016;90:109115. doi:10.1016/j.wneu.2016.02.091

31. Waly F, Alzahrani MM, Abduljabbar FH, et al. The outcome of using closed suction wound drains in patients undergoing lumbar spine surgery: a systematic review. Global Spine J. 2015;5(6):479-485. doi:10.1055/s-0035-1566288

32. Zhou J, Wang R, Huo X, Xiong W, Kang L, Xue Y. Incidence of surgical site infection after spine surgery: a systematic review and meta-analysis. Spine (Phila Pa 1976). 2020;45(3):208-216. doi:10.1097/BRS.0000000000003218

Disclosures and COI: None declared.

Corresponding Author: Tiago Amorim-Barbosa, MD, Spinal Unit, Department of Orthopaedics, Centro Hospitalar Universitário do PortoHospital de Santo António, Largo Prof. Abel Salazar, 4099-001 Porto, Portugal. Phone: 00351 968512344. Email: tiagomab2@gmail.com.

Published 3 December 2021

This manuscript is generously published free of charge by ISASS, the International Society for the Advancement of Spine Surgery. Copyright @ $\odot 2021$ ISASS. To see more or order reprints or permissions, see http://ijssurgery.com. 